\title{
High-level detection of gene amplification and chromosome aneuploidy in extracted nuclei from paraffin-embedded tissue of human cancer using FISH: a new approach for retrospective studies
}

\author{
E. Rossi, A. Ubiali, P. Balzarini, M. Cadei, F. Alpi, P.G. Grigolato \\ Department of Pathology, University of Brescia, Italy
}

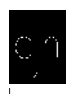

(C2005, European Journal of Histochemistry

A novel application of fluorescence in situ hybridization (FISH) to isolated nuclei is described. The method detects gene amplification and chromosome aneuploidy in extracted nuclei from paraffin-embedded tissue of human cancer with greater sensitivity and specificity than existing FISH methods. In this study, the method is applied to signal detection of the HER-2/neu (c-erbB-2) gene, whose amplification is one of the most common genetic alterations associated with human breast cancer.

Nuclei were extracted and isolated from formalin fixed, paraffin embedded tissue of 43 different carcinomas (breast, ovary, endometrium, gastrointestinal stromal tumor and malignant mesothelioma). FISH was performed both on sections and extracted nuclei of each tissue using chromosome enumeration probes (CEP) for the centromeric regions of chromosomes 8 and 17, and a locus specific identifier (LSI) for the HER-2/neu oncogene. Differences between ploidy calculated in sections and extracted nuclei were seen in 3 breast carcinomas and 1 gastrointestinal stromal tumor (GIST). Furthermore, 1 breast cancer, previously considered to be borderline for HER-2/neu gene amplification turned out to be clearly amplified. Nuclei extraction and isolation bypass all the problems related to signal interpretation in tissue sections, and the adoption of this new technique, which improves the signal quality in several neoplastic samples, is suggested.

Key words: FISH, nuclei extraction, chromosome ploidy, HER$2 /$ neu gene amplification.

Correspondence: Prof. Piergiovanni Grigolato,

II Anatomia ed Istologia Patologica, Cattedra di Anatomia Patologica, Piazzale Spedali Civili 1, 25123 Brescia, Italy. Phone +39.0303995476.

Fax +39.0303995533 .

E-mail: grigolat@med.unibs.it

Paper accepted on September 9, 2004

European Journal of Histochemistry 2005; vol. 49 issue 1 (Jan-Mar):???-???
$\mathrm{F}$ luorescence in situ hybridization (FISH) allows the identification of specific nucleic acid sequences in morphologically preserved chromosomes, cells and tissues, linking the molecular data (sequences) with traditional cytogenetics. Accurate detection of changes in structure and number of a whole chromosome or a specific chromosome region is an important prognostic and predictive factor in several human diseases (Masood and Bui, 2002; Kruger et al., 2003; Liebisch et al., 2003). FISH analysis is applied both to metaphase and interphase cells; it is performed on cell cultures, fresh tumor samples (Bentz et al., 1993; Farebegoli et al., 1999), touch imprints or cells from scraping, and on paraffin embedded archival tissue (Davison et al., 1998; Fiche et al., 1999). Using chromosome-specific probes, FISH has become an important cytogenetic tool in the evaluation of many congenital disorders, haematological malignancies and some solid tumors (Mascarello et al., 2002) because it can detect ploidy and gene amplifications, deletions or traslocations (Taylor et al. 1994; Press et al., 1997; Klijanienko et al., 1999; Li et al., 1999), and identify chimeric populations, minimal residual disease and the presence of rare neoplastic cells (Zhan et al., 1995).

One of the most common genetic alterations associated with human breast and ovary cancer is HER2/neu (c-erbB-2) amplification. The HER-2/neu (cerbB-2) gene is located on chromosome $17 q 12-21$ and encodes a protein of the Class I growth factor receptor tyrosine kinase family. Currently, it is possible to study both protein expression (immunohistochemistry) and gene amplification (FISH).

Many commercial probes work with their own protocol on $4 \mu \mathrm{m}$ histological sections (Masood et al., 1998; Depowski et al., 1999; Wang et al., 2000). These methods often encounter overlapping nuclei which make signal interpretation and counting very difficult. To avoid this problem, we extracted and isolated nuclei from formalin-fixed, paraffinembedded tissue 
Table 1. Patients.

\begin{tabular}{ll}
\hline \hline Case No. & Pathology \\
\hline 31 & Breast carcinoma \\
5 & Gastointestinal stromal tumor (GIST) \\
2 & Malignant mesothelioma \\
3 & Ovary cancer \\
2 & Endometrial cancer \\
\hline
\end{tabular}

Table 2. FISH determinations applied to each group of cases.

\begin{tabular}{lll}
\hline \hline Case No. & Tissue & Probes \\
\hline 10 & Breast carcinoma & CEP17 \\
21 & Breast carcinoma & PathVysion kit* \\
5 & Gastrointestinal stromal tumor (GIST) & Both CEP17 and CEP8 \\
2 & Malignant mesothelioma & Both CEP17 and PathVysion kit* \\
3 & Ovary cancer & PathVysion kit* \\
2 & Endometrial cancer & PathVysion kit* \\
\hline
\end{tabular}

*PathVysion kit includes two different probes (LSI HER-2/neu and CEP17).

The aim of this study was to describe a newly developed FISH protocol on nude nuclei, to compare the results obtained on extracted nuclei and tissue sections and to demonstrate the higher sensitivity and specificity of the FISH method as adapted to extracted nuclei

\section{Materials and Methods}

\section{Patients}

The tissues were obtained from the Department of Pathology of the University Hospital of Brescia from 43 selected patients classified as reported in Table 1. FISH was performed on different tissues (breast, ovary, endometrium, mesothelium, stomach). In each case, the two protocols described below were applied on both paraffin-embedded slides and extracted nuclei (see Table 2).

\section{Probes}

We performed FISH using specific probes in different tumor samples to evaluate single gene or chromosome copy number. We used a locus specific identifier probe (LSI) which targets HER-2/neu in breast, ovary and endometrial cancer, and in malignant mesothelioma, because of its widely recognised clinical significance and implications for the therapeutic approach. As we observed that chromosomes 8 and 17 are most commonly involved in breast cancer, GIST and malignant mesothelioma, we also investigated their aneuploidy using chromosome enumeration probes (CEP).

\section{FISH on tissue sections}

The protocol suggested by the probes manufacturer (Paraffin pretreatment Reagent Kit, Vysis Inc., Donwers Grove, IL, USA) was used. It includes the paraffin embedded tissue pre-treatment; the result is guaranteed only on formalin-fixed samples.

Slide preparation from formalin-fixed, paraffinembedded tissue needs the following steps: deparaffinization with Hemo-De (10 minutes, twice) and $100 \%$ ethanol (5 minutes, twice); pre-treatment with $0.2 \mathrm{~N} \mathrm{HCl}$ (20 minutes), bidistilled water (3 minutes), kit wash buffer ( 3 minutes), kit pre-treatment solution at $80^{\circ} \mathrm{C}$ (30 minutes), purified water (1 minute), and kit wash-buffer ( 5 minutes); treatment with kit protease solution at $37^{\circ} \mathrm{C}$ (10 minutes) and drying at $50^{\circ} \mathrm{C}$ (5 min); fixation in neutral buffered formalin (10 minutes) and drying at $50^{\circ} \mathrm{C}$ (5 minutes).

DNA was denatured by dipping the slides in $70 \%$ formamide/2X SSC buffer (sodium chloride and sodium citrate salts) $\mathrm{pH} 7.0-8.0$ at $73 \pm 1^{\circ} \mathrm{C}$ for 5 minutes. The slides were left in decreasing ethanol washes for 1 minute each (ethanol 70\%, 85\%, $100 \%$ ), then dried at $50^{\circ} \mathrm{C}$ for 2 minutes.

$10 \mu \mathrm{L}$ of probe kit solution (LSI HER-2/neu Spectrum Orange/CEP17 Spectrum Green PathVysion HER-2 DNA Probe Vysis Kit) or $10 \mu \mathrm{l}$ of diluted probe (CEP17 Spectrum Green DNA probe, Vysis or CEP8 Spectrum Orange DNA probe, Vysis) were applied to the target area and coverslips were placed on the slides. Humidified chamber pre-warmed at $37^{\circ} \mathrm{C}$ overnight followed.

Samples were then briefly washed in the posthybridization buffer (2X SSC and $0.3 \%$ Nonidet P40, Sigma Aldrich, Germany) at room temperature and left at $72 \pm 1^{\circ} \mathrm{C}$ for 2 minutes in the same solution. They were finally dried in a dark room at room temperature, mounted and counterstained with kit DAPI/antifade (PathVysion HER-2 DNA Probe Kit, Vysis Inc.).

\section{FISH on isolated nuclei}

Nuclei extraction was performed on $40 \mu \mathrm{m}$ thick sections of formalin-fixed, paraffin-embedded tissue, after morphological evaluation of a hematoxylin/eosin stained slide in order to select a wholly neoplastic area.

The sections of neoplastic tissue were treated with xylene overnight and rehydrated through a decreasing alcohol scale (ethanol 100\%, 85\%, $70 \%, \mathrm{H}_{2} \mathrm{O}$ ). After 2 hours of enzymatic digestion at 
$37^{\circ} \mathrm{C}$ with $0.005 \%$ pepsin (Roche, Germany), the samples were filtered through $50 \mu \mathrm{m}$ nylon pores and centrifuged for 8 minutes at 1800 RPM. The pellet was resuspended in phosphate buffer saline (PBS). Twenty to forty $\mu \mathrm{L}$ (depending on cell concentration) of nuclear suspension were put on a clean slide, air dried and fixed for 10 minutes with acetic acid/methanol (1:3). Once fixed, the samples can be stored at room temperature for several months.

One slide was stained with hematoxylin to assess the relative quantity and quality of nuclei. The other slides were pre-treated in 2X SSC for 15 minutes at $37^{\circ} \mathrm{C}$ and gradually rehydrated to $70 \%$ ethanol.

They were then treated with $0.1 \mathrm{mM}$ citric acid $\left(\mathrm{pH} \mathrm{6)}\right.$, kept at $85^{\circ} \mathrm{C}$ for 1 hour and placed in $0.005 \%$ trypsin solution (Roche, Germany) for 10 minutes at $37^{\circ} \mathrm{C}$. Another rehydration in $70 \%$ alcohol and air drying followed. Then, $10 \mu \mathrm{L}$ of probe kit solution (LSI HER-2/neu Spectrum Orange/CEP17 Spectrum Green PathVysion HER-2 DNA Probe PathVysion HER-2 DNA Probe Kit, Vysis) or $10 \mu \mathrm{L}$ of diluted probe (CEP17 Spectrum Green DNA probe, Vysis or CEP8 Spectrum Orange DNA probe, Vysis) were applied.

Slides were covered with a coverslip. DNA was denatured at $80^{\circ} \mathrm{C}$ for 3 minutes and incubated overnight at $37^{\circ} \mathrm{C}$ in a pre-warmed humidified chamber. The day after, the slides were briefly washed in 2X SSC with $0.1 \% \mathrm{NP} 40$ at pH 7, kept at room temperature until the coverslips floated off and put in the solution described above for 2 minutes at $70^{\circ} \mathrm{C}$. Finally, they were treated in PBS, mounted and counterstained with DAPI (Sigma Aldrich, Germany)/antifade (Vectashield, Vector, USA) or propidium iodide (Sigma Aldrich, Germany)/antifade.

\section{Signal enumeration and data interpretation}

For each chromosome enumeration probe and each sample, at least 200 non overlapping interphase nuclei were evaluated (Mazzucchelli et al., 2000). We set the threshold for complete polysomy at $20 \%$ of nuclei with more than two signals (Balazs et al., 1995; Mendelin et al., 1999; Visscher et al., 2000). Centromeric signals were counted using an epifluorescent microscope (Nikon Eclipse E600), equipped with selective filters for the fluorochromes used. FISH images were captured using a Nikon digital camera (X600 and X1000 magnification). They were further elaborated with the Nikon ACT-1 2.11 image analysis software.

LSI probe signals were evaluated in 60 non overlapping interphase nuclei within an area of invasive carcinoma [Hoang et al., 2000; Ellis et al., 2000]. HER-2/neu evaluation was performed with the PathVysion kit using two fluorescent DNA probes (LSI HER-2/neu and CEP17). The expected ratio of HER-2/neu and CEPI7 is less than 2.0 for the unamplified specimen and more than 2.0 for the amplified. This ratio is applied in order to distinguish true amplification from chromosome aneuploidy [Pauletti et al., 1996; Vang et al., 2000].

\section{Statistics}

To evaluate discrepancies between results on slides and extracted nuclei, a simple statistical analysis based on coupled, two-tailed Student's t test (threshold 0.05) was performed.

\section{Results}

Making a comparison between the results of FISH performed on extracted nuclei and on sections, we considered separately DNA ploidy and gene amplification. A slight difference between

Table 3. Evaluation of polysomy by count of FISH chromosome 8 and chromosome 17 enumeration probes (CEP) in isolated nuclei and sections. The threshold for chromosome aneuploidy is set to $20 \%$ of total polysomic nuclei.

\begin{tabular}{lcccc}
\hline \hline CASE & \multicolumn{2}{c}{ CEP 17 } & \multicolumn{2}{c}{ CEP 8 } \\
& $\begin{array}{c}\text { Extracted Nuclei } \\
\text { Polysomy } \%\end{array}$ & $\begin{array}{c}\text { Slide } \\
\text { Polysomy } \%\end{array}$ & $\begin{array}{c}\text { Extracted Nuclei } \\
\text { Polysomy \% }\end{array}$ & $\begin{array}{c}\text { Slide } \\
\text { Polysomy \% }\end{array}$ \\
\hline BR1 & 79.91 & 50.65 & NP & NP \\
BR2 & 88.76 & 57.21 & NP & NP \\
BR3 & $\mathbf{3 8 . 6 1}$ & $\mathbf{1 8 . 4 9}$ & NP & NP \\
BR4 & $\mathbf{2 9 . 5 4}$ & $\mathbf{1 7 . 7 5}$ & NP & NP \\
BR5 & $\mathbf{3 1 . 3 2}$ & $\mathbf{1 9 . 5 3}$ & NP & NP \\
BR6 & 0 & 0 & NP & NP \\
BR7 & 0 & 0 & NP & NP \\
BR8 & 0 & 0.10 & NP & NP \\
BR9 & 0 & 0.98 & NP & NP \\
BR10 & 0 & 1.02 & NP & NP \\
GIST1 & $\mathbf{5 6 . 1}$ & $\mathbf{1 9 . 2 6}$ & $\mathbf{7 4 . 0 4}$ & $\mathbf{5 0 , 6 5}$ \\
GIST2 & 8.86 & 8.15 & 26.78 & 20,04 \\
GIST3 & 9.58 & 10.30 & 67.44 & 48,52 \\
GIST4 & 10.60 & 8.21 & 12.20 & 10,70 \\
GIST5 & 2.24 & 0.53 & 9.35 & 5,33 \\
MM1 & 48.51 & 31.70 & NP & NP \\
MM2 & 31.50 & 28.54 & NP & NP \\
& & & &
\end{tabular}

$B R=$ Breast cancer $; G I S T=$ Gastrointestinal stromal tumor $M M=$ Malignant mesothelioma; $N P=$ Not performed; In bold type: cases with diverging results in ploidy. 

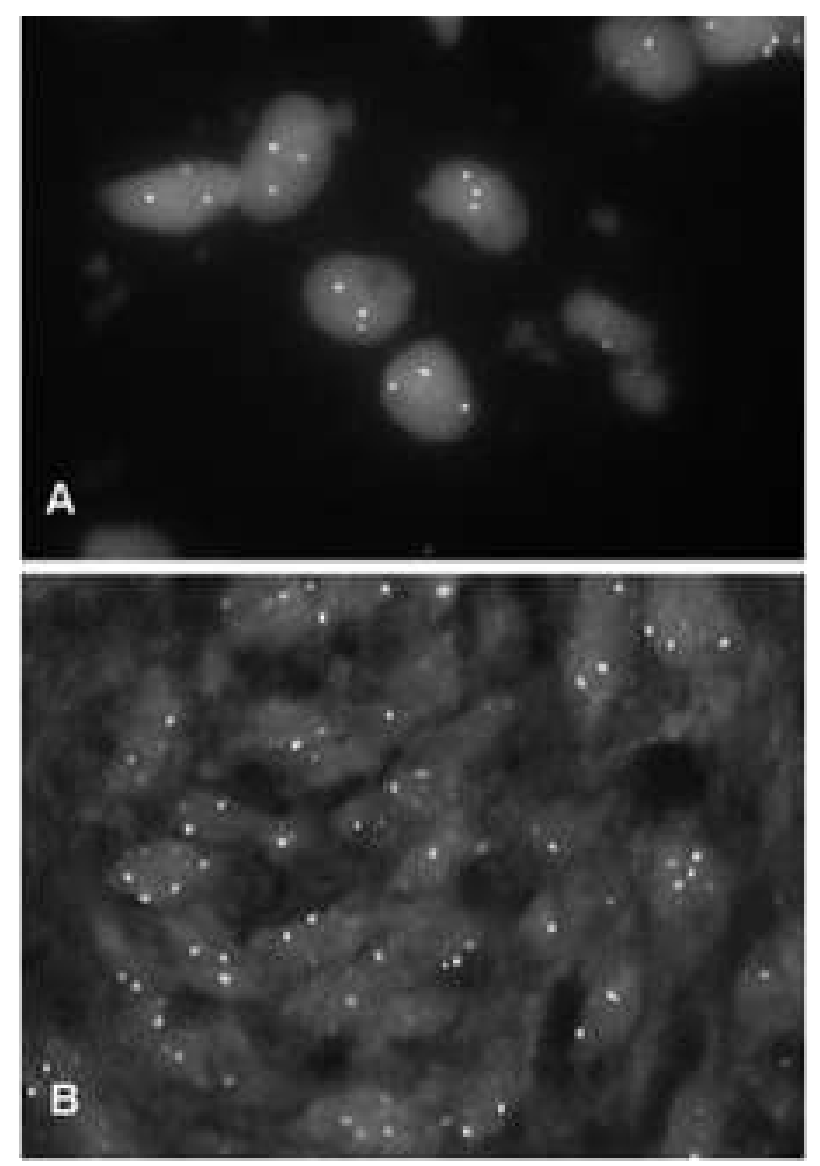

Figure 1. FISH for CEP17 performed on extracted nuclei (A) and on histological section (B) of a GIST case. The signals in A are much more readable than in $B$, thus making the count easier.

ploidy evaluated on sections and on extracted nuclei was noticed (Table 3 ) which was statistically significant $(p=0.007)$ on CEP17. Statistics could not be performed on CEP8 because of the low samples number.

In 3 breast cancers (cases BR3, BR4, BR5), the percentages were above threshold for chromosome 17 polysomy ( $>20 \%$ ) in the extracted nuclei, and lower in the sections $(<20 \%)$. In addition, 1 of the 5 GIST cases (GIST1) showed this difference between extracted nuclei and sections for chromosome 17 polysomy. In the same samples, the percentages of polysomic nuclei for chromosome 8 were above threshold in both the extracted nuclei and the sections, although they were much lower in the sections. Comparison between the FISH results on extracted nuclei and sections of the GISTI case is shown in Figure 1.

In Table 4, the amplification values calculated for HER-2/neu protooncogene, based on HER-2/neu to CEP17 ratio, are reported. There are no discrepancies between extracted nuclei and sections, except in 1 out of 22 breast cancers (case BR14), which is amplified only in the slide. Otherwise, considering the numeric HER-2/neu to CEP17 ratio, statistics prove to be significant for a discrepancy between the results of the two methods $(p=0.015)$. This discrepancy does not affect the final response (amplified vs not amplified), because values remain above or under the given threshold.

Figures 2 and 3 show the results on extracted nuclei and histological sections, respectively.

\section{Discussion}

In the present work, a new protocol is described for FISH based on the extraction of nuclei from formalin-fixed, paraffin-embedded samples. The nuclear suspension makes the fluorescent spots easier to count both in the evaluation of chromosome ploidy (CEP count) and in the calculation of the HER-2/neu to CEPI7 ratio (LSI and CEP count).

Table 4. Evaluation of HER-2/neu gene amplification by calculation of HER-2/neu LSI to CEP17 ratio in isolated nuclei and sections. The threshold for gene amplification is set at 2.0.

\begin{tabular}{|c|c|c|c|c|}
\hline \multirow[t]{2}{*}{ Case } & \multicolumn{2}{|c|}{ Extracted Nuclei } & \multicolumn{2}{|c|}{ Slide } \\
\hline & $\begin{array}{l}\text { LSI HER-2/NEU } \\
\text { to CEP } 17 \text { ratio }\end{array}$ & Result & $\begin{array}{l}\text { LSI HER-2/NEU } \\
\text { to CEP } 17 \text { ratio }\end{array}$ & Result \\
\hline BR11 & 1.29 & Not amplified & 1.15 & Not amplified \\
\hline BR12 & 1.15 & Not amplified & 1.07 & Not amplified \\
\hline BR13 & 1.06 & Not amplified & 1.05 & Not amplified \\
\hline BR14 & 1.88 & Not amplified & 2.02 & Amplified \\
\hline BR15 & 8.87 & Amplified & 8.91 & Amplified \\
\hline BR16 & 2.60 & Amplified & 2.45 & Amplified \\
\hline BR17 & 1.00 & Not amplified & 1.00 & Not amplified \\
\hline BR18 & 1.20 & Not amplified & 1.00 & Not amplified \\
\hline BR19 & 4.08 & Amplified & 4.50 & Amplified \\
\hline BR20 & 4.90 & Amplified & 5.22 & Amplified \\
\hline BR21 & 2.40 & Amplified & 2.33 & Amplified \\
\hline BR22 & 1.10 & Not amplified & 1.00 & Not amplified \\
\hline BR23 & 1.05 & Not amplified & 1.00 & Not amplified \\
\hline BR24 & 2.20 & Amplified & 2.21 & Amplified \\
\hline BR25 & 1.20 & Not amplified & 1.10 & Not amplified \\
\hline BR26 & 2.38 & Amplified & 2.30 & Amplified \\
\hline BR27 & 6.00 & Amplified & 5.80 & Amplified \\
\hline BR28 & 3.69 & Amplified & 2.99 & Amplified \\
\hline BR29 & 1.00 & Not amplified & 1.00 & Not amplified \\
\hline BR30 & 1.00 & Not amplified & 1.00 & Not amplified \\
\hline BR31 & 1.91 & Not amplified & 1.50 & Not amplified \\
\hline EN1 & 2.60 & Amplified & 2.45 & Amplified \\
\hline EN2 & 2.60 & Amplified & 2.37 & Amplified \\
\hline MM1 & 1.79 & Not amplified & 1.50 & Not amplified \\
\hline MM2 & 1.23 & Not amplified & 1.00 & Not amplified \\
\hline OV1 & 1.10 & Not amplified & 1.00 & Not amplified \\
\hline ov2 & 1.30 & Not amplified & 1.00 & Not amplified \\
\hline OV3 & 1.20 & Not amplified & 1.00 & Not amplified \\
\hline
\end{tabular}

$B R=$ Breast cancer $; E N=$ Endometrial cancer; $M M=$ malignant mesothelioma; $O \mathrm{~V}=$ Ovarian cancer; $A$ single case with diverging results in gene amplification is outlined in bold. 

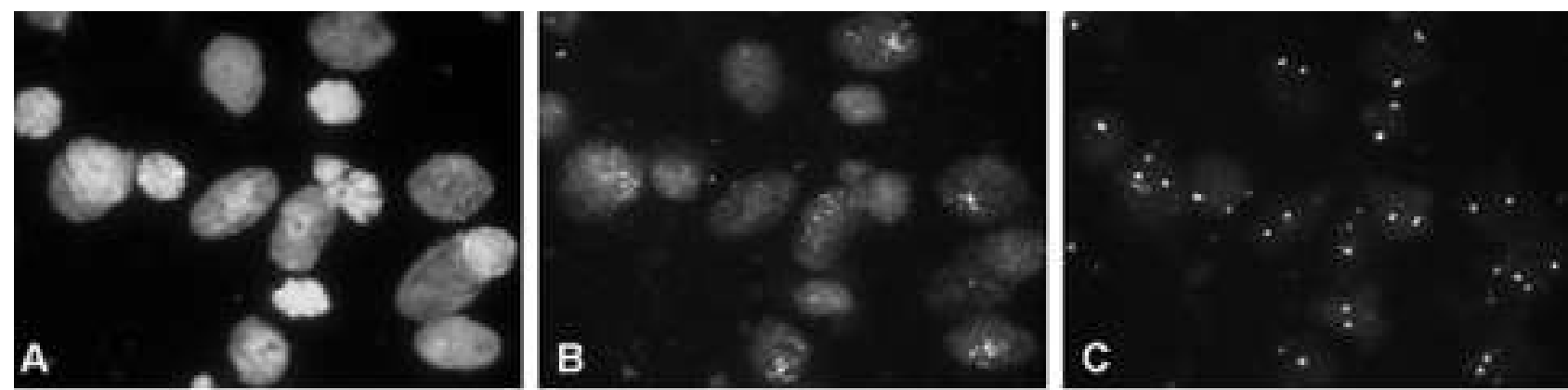

Figure 2. FISH for the calculation HER-2/neu to CEP17 ratio performed on extracted nuclei. A) DAPI staining of the isolated nuclei. B) LSI signal for HER-2/neu. C) CEP17 signal.
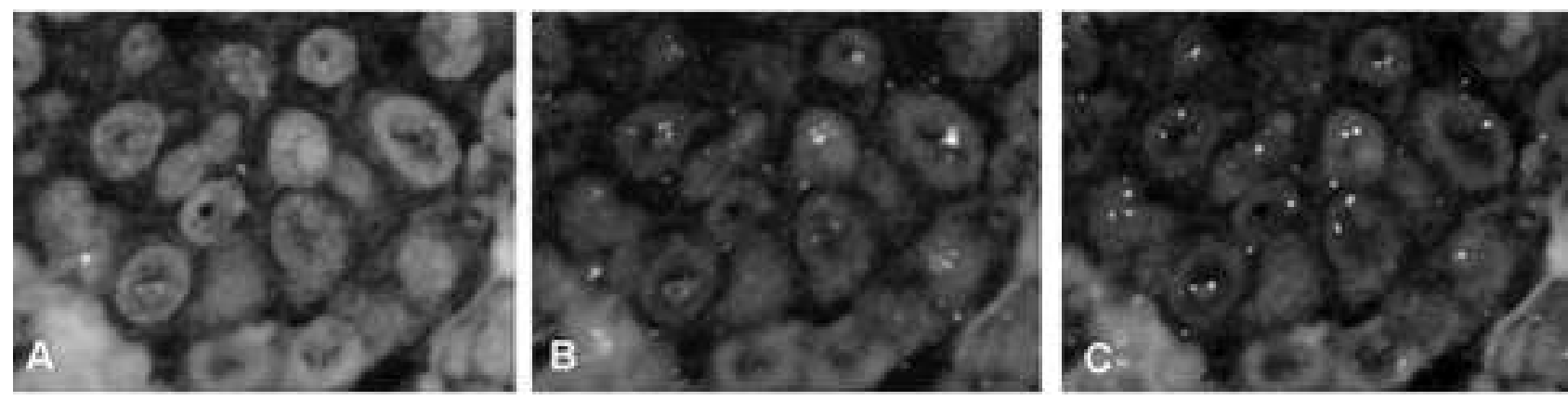

Figure 3. FISH for the calculation HER-2/neu to CEP17 ratio performed on histological section. A) DAPI staining of the section. B) LSI signal for HER-2/neu. C) CEP17 signal.

This method avoids 1), the signal overlapping typically found in sections, and 2), the background noise; in this way influencing the final result in some borderline cases. In fact, three breast cancers and one GIST showed aneuploid signals for chromosome 17 only after extraction and isolation of the nuclei. And, in the evaluation of HER-2/neu protooncogene amplification, 1 out of the 22 breast cancers, previously considered borderline because the FISH signal count was ambiguous, turned out to be amplified for HER-2/neu only on isolated nuclei.

Problems with histological sections probably arise from the relatively high number of cut nuclei, especially in thin sections $(2 \mu \mathrm{m})$. Immediate consequences are the signal loss and, particularly in cerbB-2 counts, the inability to recognize weakly amplified signals. The operator needs an increased number of counted nuclei and more complex statistical studies, but they are often time consuming and error prone (Xing et al., 1996; Masood et al., 1998; Burger et al., 2001; Jordan et al., 2001), while nuclei extraction and isolation bypass all these problems.

In conclusion, we suggest the use of this protocol based on nuclei extraction and isolation. It can solve several problems often found when evaluating chromosome ploidy and single gene amplification by means of FISH on tissue sections by improving the signal quality in several types of neoplastic samples studied for diagnostic and research proposes. This improvement not only affects the number of signals counted in the nuclei, but also the intensity of the spots, which tends to be more clearly readable.

\section{Acknowledgements}

We wish to thank Dr. Vincenzo Villanacci for having provided us with the GIST cases and for his helpful supervision.

\section{References}

Balazs M, Matsumura K, Moore D, Pinkel D, Gray JW, Waldman FM. Karyotypic heterogeneity and its relation to labelling index in interphase breast tumor cells. Cytometry 1995; 20:62-73.

Bentz M, Schroder M, Herz M, Stilgenbauer S, Lichter P, Dohner H. Detection of trisomy 8 on blood smears using fluorescence in situ hybridization. Leukaemia 1993; 7: 752-7.

Davison JM, Morgan TW, Hsi BL, Xiao S, Fletcher JA. Subtracted, unique-sequence, in situ hybridization: experimental and diagnostic applications. Am J Pathol, 1998; 153:1401-9

Depowski PL, Brien TP, Sheehan CE, Stylos S, Johnson RL, Ross JS. Prognostic significance of $\mathrm{p} 34^{\mathrm{cdc} 2}$ cyclin-dependent kinase and MIBI overexpression, and HER-2/neu gene amplification detected by fluorescence in situ hybridization in breast cancer. Am J Clin Pathol 1999; 112:459-69.

Ellis I0, Dowsett M, Barlett J, Walker R, Cooke T, Gullik W, et al. Recommendations for HER2 testing in the UK. 2000, J Clin Pathol 53:890-2

Farebegoli F, Ceccarelli C, Santini D, Baldini N, Taffurelli M, Marrano 


\section{E. Rossi et al.}

D, et al. c-erbB-2 over-expression in amplified and non-amplified breast carcinoma sample. Int J Cancer 1999; 84:273-7.

Fiche M, Avet-Loiseau H, Heymann MF, Moussaly F, Digabel C, Joubert $\mathrm{M}$, et al. Genetic alteration in early-onset invasive breast carcinomas: correlation of c-erbB-2 amplification and tumor phenotype. Int J Cancer 1999; 84:511-5.

Hoang MP, Sahin AA, Ordinez NG, Sneige N. HER-2/neu gene amplification compared with HER-2/neu protein overexpression and interobserver reproducibility in invasive breast carcinoma. Am J Clin Pahol 2000; 113:852-9.

Klijanienko J, Couturier J, Galut M, El-Naggar AK, Maciorowski Z, Padoy $E$, et al. Detection and quantitation by fluorescence in situ hybridization (FISH) and image analysis of HER-2/neu gene amplification in breast cancer fine-needle samples. Cancer 1999; 87:3128.

Kruger S, Mess F, Bohle A, Feller AC. Numerical aberrations of chromosome 17 and the 9p21 locus are independent predictors of tumor recurrence in non-invasive transitional cell carcinoma of the urinary bladder. Int J Oncol 2003, 23:41-8

Li JY, Gaillard F, Moreau A, Harousseau JL, laboisse C, Milpied N, et al. Detection of Translocation $\mathrm{t}(11 ; 14)(\mathrm{q} 13 ; \mathrm{q} 32)$ in Mantle Cell Lymphoma by Fluorescence in Situ Hybridization. Am J Pathology 1999; 154:1449-52.

Liebisch P, Viardot A, Bassermann N, Wendl C, Roth K, Goldschmidt $\mathrm{H}$, et al. Value of comparative genomic hybridization and fluorescence in situ hybridization for molecular diagnostics in multiple myeloma. Br J Haematol 2003 Jul;122:193-201.

Mascarello JT, Brothman AR, Davison K, Dewald GW, Herrman M, McCandless D, Park JP, Persons DL, Rao KW, Schneider NR, Vance $\mathrm{GH}$ and Cooley LD. Proficiency testing for laboratories performing fluorescence in situ hybridization with chromosome-specific DNA probes. Arch Pathol Lab Med 2002; 126:1458-62.

Masood S, Bui M M, Yung JF, Mark HF, Wong EY, Birkmeier JM, et al. Reproducibility of LSI HER-2/neu SpectrumOrange and CEP17 SpectrumGreen Dual Color deoxyribonucleic acid probe kit. For enumeration of gene amplification in paraffin-embedded specimens: a multicenter clinical validation study. Ann Clin Lab Sci 1998; 28:215-23.

Masood S, Bui MM. Prognostic and predictive value of HER2/neu oncogene in breast cancer. Microsc Res Tech. 2002 0ct 15;59:1028.

Mazzucchelli L, Burckhardt E, Hirsiger H, Kappeler A, Laissue JA. Interphase cytogenetics in oncocytic adenomas and carcinomas of the thyroid gland. Human Pathol 2000;31:854-9

Mendelin J, Grayson McC, Wallis T, Vissher W. Analysis of chromosome aneuploidy in breast carcinoma progression by using fluorescence in situ hybridization. Lab Invest 1999; 79:387-93.

Pauletti G, Godolphin W, Press MF, Slamon DJ. Detection and quantitation of HER-2/neu gene amplification in human breast cancer archival material using fluorescence in situ hybridization Oncogene 1996;13:63-72.

Press MF, Bernstein L, Thomas PA, Meisner LF, Zhou JY, Ma Y, et al. HER-2/neu gene amplification characterised by fluorescence in situ hybridization: poor prognosis in node-negative breast carcinomas. $J$ clin Oncol 1997; 15:2894-904.

Taylor CP, McGuckin AG, Bown NP, Reid MM, Malcom AJ, Person $A D$, et al. Rapid detection of prognostic genetic factors in neuroblastoma using fluorescence in situ hybridization on tumor imprints and bone marrow smears. United Kingdom Children's Cancer Study Group" Br J Cancer 1994; 69:445-51.

Vang R, Cooley LD, Herrison WR, Reese T, Abrams J. Immunohistochemical determination of $\mathrm{HER}-2$ /neu expression in invasive breast carcinoma. Am J Clin Pathol 2000;113:669-74.

Visscher D, Jimenez RE, Grayson III McC, Mendelin J, Wallis T. $\mathrm{Histopathologic} \mathrm{analysis} \mathrm{of} \mathrm{chromosome} \mathrm{aneuploidy} \mathrm{in} \mathrm{ductal} \mathrm{carci-}$ noma in situ. Human Pathol 2000; 31:201-7.

Wang S, Saboorian MH, Frenkel E, Hynan L, Gokaslan ST, Ashfaq R. Laboratory assessment of the status of HER-2/neu protein and oncogene in breast cancer specimens : comparison of immunohistochemistry assay with fluorescence in situ hybridisation assays. J Clin Pathol 2000; 53:374-81

Zhan L, Chang KS, Estey EH, Hayes K, Deisseroth AB, Liang JC. Detection of residual leukaemic cells in patients with acute promyelocytic leukaemia by the fluorescence in situ hybridisation method. Blood 1995; 85:495-9. 